\title{
SYNTHESIS AND USE OF GLYCIDYL METHACRYLATE- G-POLY (ETHYLENE TEREPHTHALATE) FIBER CONTAINING IMINODIACETATE GROUPS FOR THE HIGHLY EFFECTIVE REMOVAL OF BASIC DYE
}

\author{
METIN ARSLAN and KÜBRA GÜNAY \\ Department of Chemistry and Chemical Processing Technologies \\ Kırıkkale Vocational High School \\ Kırıkkale University \\ Yahsihan, 71450 Kırıkkale \\ Turkey \\ e-mail: marslan@hotmail.com \\ Graduate School of Natural and Applied Sciences \\ Kirıkkale University \\ Yahsihan, 71450 Kırıkkale \\ Turkey
}

\begin{abstract}
A novel chelating fiber adsorbent was synthesized by reacting diethyl iminodiacetate (DEIDA) with glycidyl methacrylate-g-poly (ethylene terephthalate) fiber (GMA-g-PET) and then hydrolysis of the ester introduced by $\mathrm{HNO}_{3}$ for the removal of methylene blue (MB) dye from aqueous solution. Various factors affecting the removal behaviour such as graft yield, $\mathrm{pH}$, contact time, and initial concentration were investigated. The increase in the amount hydroxyl and iminodiacetate groups on glycidyl methacrylate-g-poly (ethylene
\end{abstract}

Keywords and phrases: grafting, chelating fiber, iminodiacetate, methylene bule.

Received September 26, 2018

(C) 2018 Scientific Advances Publishers 
terephthalate) fiber (IDA-GMA-g-PET) significantly improved the removal amount of MB. It was observed that $100 \%$ of MB dye was removed by IDAGMA-g-PET fiber in 45 min contact time.

\section{Introduction}

Synthetic dyes are widely used in many industries, such as textile, dying, printing, cosmetics, food colouring, paper making etc., which are released directly into the environment without any pre-treatment in developing countries. The industrial wastewater containing synthetic dyes are among the most dangerous organic pollutants. The presence of synthetic dyes in wastewater has caused serious concerns to people and environment due to their toxicity and carcinogenicity [1]. The procedure of synthetic dye-contaminated wastewater is very difficult since they are extremely soluble and stable in wastewater. Moreover, they are nondegradable and cannot be decomposed in municipal water treatment plants [2, 3]. Therefore, it is necessary to remove synthetic dyes from industrial wastewater prior to their discharge. Researchers are concerned over the treatment of synthetic dyes-rich wastewater. So far, a lot of methods have been developed, such as coagulation and flocculation [4], membrane separation [5], oxidation or ozonation [6], electro-coagulation [7], and adsorption [8]. The adsorptive removal of synthetic dyes is the most widely used process due to its simplicity, low cost, efficiency, and high selectivity [9]. Many adsorbents have been developed. However, most of these adsorbents show a limited adsorption capacity because they do not have enough surface area, functional groups and some problems, including high cost, difficulties of separation and regeneration of adsorbents from wastewater. So, it is highly desirable to developed novel adsorbents with large surface area, active functional groups, high adsorption capacity, and fast separation [1].

The adsorption capacity of synthetic dyes is highly depended on the accessible chelating groups on adsorbent surfaces. Therefore, chelating polymeric fibers are increasingly used in the removal of synthetic dyes due to their high adsorption capacities, selectivity, fast separation, and 
continuity reuse. Chelating polymeric fibers possess many reactive ionic functional groups such as carboxylic acid, amine, hydroxyl, epoxy and pyridine. They have greatly advanced this field and may be used as an alternative adsorbent for the removal of synthetic dyes from water. Surface modification of polymeric fibers by grafting is a useful method for the synthesis of adsorbent with specific surface and structural properties. It has been developed chemical and mechanical properties of polymeric fibers by grafting with different vinyl monomers and increases water absorbency, dyeability and adsorption capacity of polymeric fibers [10-12].

Iminodiacetate (IDA) resins have been widely used to remove toxic heavy metal ions from wastewater. However, one of their disadvantages is slow kinetics in the adsorption process [13-15]. In order to obtain IDAchelating polymeric fibers with fast kinetic and high removal capacities have been studied. There are not reports on functioned IDA onto poly (ethylene terephthalate) fibers (PET) with high specific surface. In the present work, glycidyl methacrylate (GMA) was grafted onto PET fibers by chemical method (GMA-g-PET). The epoxy groups of GMA-g-PET fibers was converted to IDA polymeric fibers adsorbents using diethyl iminodiacetate by chemical reaction (DEIDA-GMA-g-PET) and then hydrolysis of the ester introduced by $\mathrm{HNO}_{3}$ (IDA-GMA-g-PET). The removal, desorption and reuse of IDA-GMA-g-PET fibers toward methylene blue (MB) were examined.

\section{Experimental}

\subsection{Materials}

The polyester (PET) fibers (122 dTex, middle drawing) were SASA Co. (Turkey) product. The models were cleared for $10 \mathrm{~h}$ by dimethyl ketone and dried in an oven at surroundings temperature. Benzoyl peroxide was doubly recrystallized from chloroform in methanol and dried. Other reagents were used like received. Total chemicals were Merck products. 


\subsection{Swelling procedure}

The fibers were immersed in dichloroethane at $90^{\circ} \mathrm{C}$ for $2 \mathrm{~h}$. The swollen the fibers was wiped with cleansing tissue to remove dichloroethane and place into the polymerization medium [16].

\subsection{Graft copolymerization process}

Graft copolymerization was allotted in a three-necked polymerization glass tube. The polymerization tube containing the PET fiber about $0.3 \mathrm{~g}$, acceptable quantity of GMA monomer and benzoyl peroxide at needed concentration in $2 \mathrm{~mL}$ dissolving agent (acetone) was created up to $20 \mathrm{~mL}$ with demineralized water. The polymerization tube was instantly placed into the water bathtub adjusted to the polymerization temperature (at $\left.70^{\circ} \mathrm{C}\right)$. At the tip of the preset chemical change time $(2 \mathrm{~h})$, the grafted fibers were taken out and residual solvent, monomer and homopoly (GMA) were removed with acetone for $24 \mathrm{~h}$. The modified fibers were then dried at $25^{\circ} \mathrm{C}$ for $24 \mathrm{~h}$ and weighed. The graft yield (GY) was calculated from the weight increase in grafted fibers as follows:

$$
G Y(\%)=\left[\left(m_{g}-m_{i}\right) / m_{i}\right] \times 100,
$$

where $m_{i}$ and $m_{g}$ represent the weights of the original and grafted fibers, respectively [17].

\subsection{Preparation of IDA-GMA-g-PET fibers}

GMA-g-PET fibers were immersed in $0.5 \mathrm{M}$ diethyl iminodiacetate (DEIDA) in 50\% ethanol. The contents were shaken at $110 \mathrm{rpm}$ for $4 \mathrm{~h}$ at $80^{\circ} \mathrm{C}$ using orbital shaker (Selectra). Then, the resulting PET fibers were separated from the DEIDA solution, washed with deionized water. Subsequently, the hydrolysis of the introduced DEIDA was carried out by heating $\left(80^{\circ} \mathrm{C}\right)$ the resulting PET fibers in $1 \mathrm{M} \mathrm{HNO}$ for $4 \mathrm{~h}$. IDA-GMA-gPET fibers were washed repeatedly with deionized water. IDA-GMA-gPET fibers were vacuum-dried at $50^{\circ} \mathrm{C}$ for $24 \mathrm{~h}$ and weighed. The amount 
of IDA (\%) was calculated from the weight increase in IDA-GMA-g-PET fibers as follows:

$$
\operatorname{IDA}(\%)=\left[\left(w_{s}-w_{g}\right) / w_{s}\right] \times 100,
$$

where $w_{s}$ and $w_{g}$ denote the weights grafted PET fibers and IDA-GMAg-PET fibers, respectively [10].

\subsection{FTIR spectra}

FTIR spectras of ungrafted, GMA grafted and IDA-GMA-g-PET fibers were obtained. The fibers were cut into roughly $1 \mathrm{~mm}$ size, mixed with $\mathrm{KBr}$, and then pressed. The spectra were recorded on a Bruker Vertex 70V FTIR photometer.

\subsection{Scanning electron microscopy (SEM) analysis}

SEM analysis was carried out to research the surface morphology of original and GMA-g-PET fibers employing a JEOL Model JSM 5600 scientific instrument. The fibers covered a thin evaporated layer of gold and were performed.

\subsection{Sorption of $\mathrm{MB}$}

Volume of $25 \mathrm{~cm}^{3}$ of MB solution was added onto 0.1g of IDA-GMA-gPET fibers in $50 \mathrm{~mL}$ Erlenmeyer. The contents were shaken at $125 \mathrm{rpm}$ for a predetermined period of time at $25^{\circ} \mathrm{C}$ using orbital shaker (Selectra). The loaded adsorbent was separated by centrifugation and washed gently. After the MB concentration of supernatant was adjusted to $6.8 \mathrm{pH}$ value. After it was measured by using UV/Visible spectrophotometer ( $\mathrm{pH}=6.8, \lambda=665 \mathrm{~nm}$, Perkin Elmer Lambda 25). Calibration curves were plotted between absorbance and concentration of the standard dye solutions. The adsorption capacity of the fibers was evaluated by using the following expression:

$$
q=\left(C_{0}-C\right) V / m,
$$


where $q$ is the amount of dye adsorbed onto unit mass of the PET fibers $\left(\mathrm{mg} \mathrm{g}^{-1}\right), C_{0}$ and $C$ are the concentration of the $\mathrm{MB}$ in the initial solution and in the aqueous phase after adsorption treatment for a certain period of time $\left(\mathrm{mgL}^{-1}\right) ; V$ is the volume of the MB solution used (L); and $m$ is the amount of the PET fibers used (g), respectively.

\subsection{Desorption and reuse}

Desorption of cationic dye were studied with $25 \mathrm{~mL}$ of $1 \mathrm{M} \mathrm{HNO}_{3}$ solution. The dye was desorbed, then diluted with water and analysed as above. The desorption percent was calculated employing Equation (4).

$\%$ Desorption $=\frac{\text { Amount of cationic dye }(\mathrm{mg}) \text { desorbed }}{\text { Adsorbed amount of cationic dye }(\mathrm{mg}) \text { by adsorbent }} \times 100$.

The sorption-desorption process was repeated ten times using IDA-GMAg-PET fibers.

\section{Results and Discussions}

\subsection{Characterization of the fibers adsorbent}

Chemical grafting of GMA onto PET, grafting mechanism and characterizing was illustrated with our previous work [17]. The surface chemical structures of original, GMA-g-PET and IDA-GMA-g-PET fibers have been analysed by FT-IR spectroscopy and is displayed in Figure 1. The FT-IR spectra of original PET fibers displayed peaks owing to $\mathrm{C}=\mathrm{O}$ (at $1712 \mathrm{~cm}^{-1}$ ), $\mathrm{C}=\mathrm{C}$ and aliphatic $\mathrm{C}-\mathrm{H}$ (at 1411 and $1578 \mathrm{~cm}^{-1}$ ) of PET fibers. After the grafting with GMA, the spectrum of the GMA-g-PET fiber changed. The new peak at $905 \mathrm{~cm}^{-1}$ in the spectrum is owing to the resonance peak of the epoxy groups. After IDA functionalization of GMAg-PET fibers, the new peak disappeared $\left(905 \mathrm{~cm}^{-1}\right)$ and the new peak at $1634 \mathrm{~cm}^{-1}$ in the spectrum emerged owing to carboxylate ions, which is 
assigned to the absorption of IDA-GMA units and confirming the reaction of epoxy on GMA-g-PET fibers with amino groups in the IDA. In addition, the new peak at $3349 \mathrm{~cm}^{-1}$ shown in Figure 1 was attributed to the $\mathrm{O}-\mathrm{H}$ peak $[17,18]$.

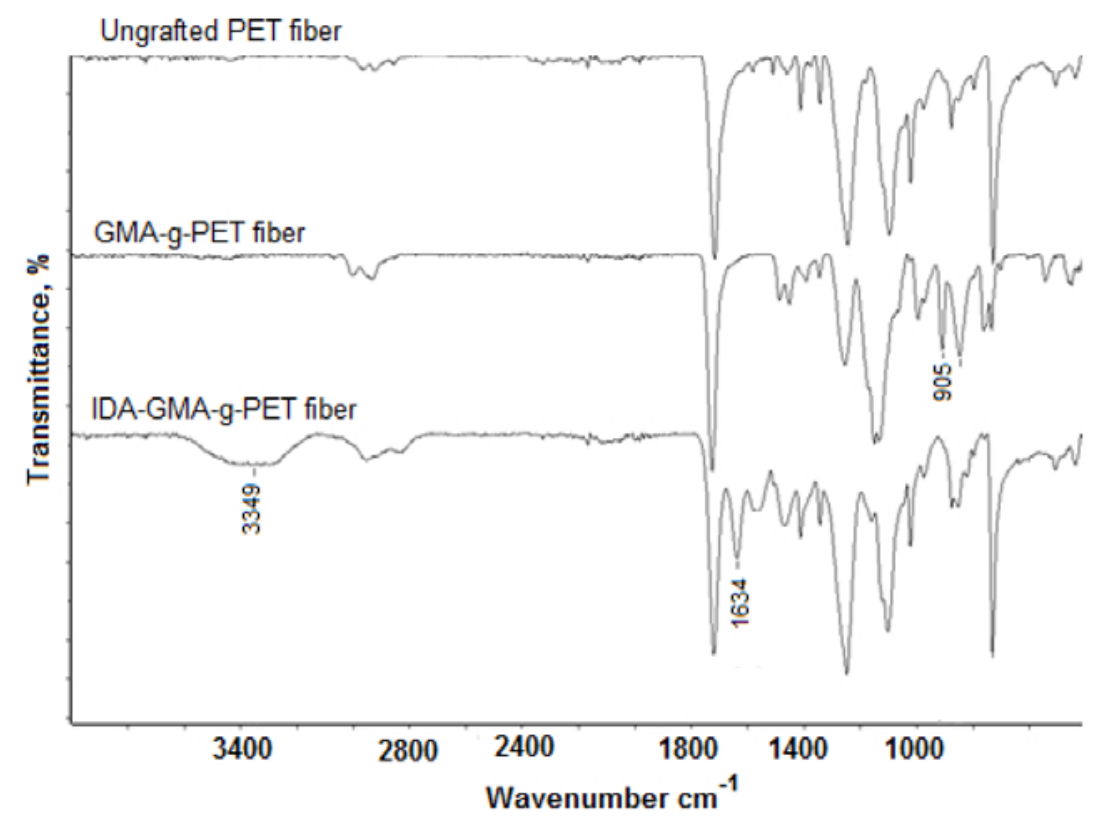

Figure 1. FT-IR spectra of PET fibers.

The scanning electron micrographs of original and GMA-g-PET fibers are shown in Figure 2. It is clear from the SEM results that, the ungrafted PET fiber surface (Figure 2(a)) has a smooth and relatively homogeneous appearance. The grafted side chain, GMA, seems to form microphases attached to the PET back-bone and caused a heterogeneous appearance in the graft copolymer (Figure 2(b)), and showing proof of grafting. 

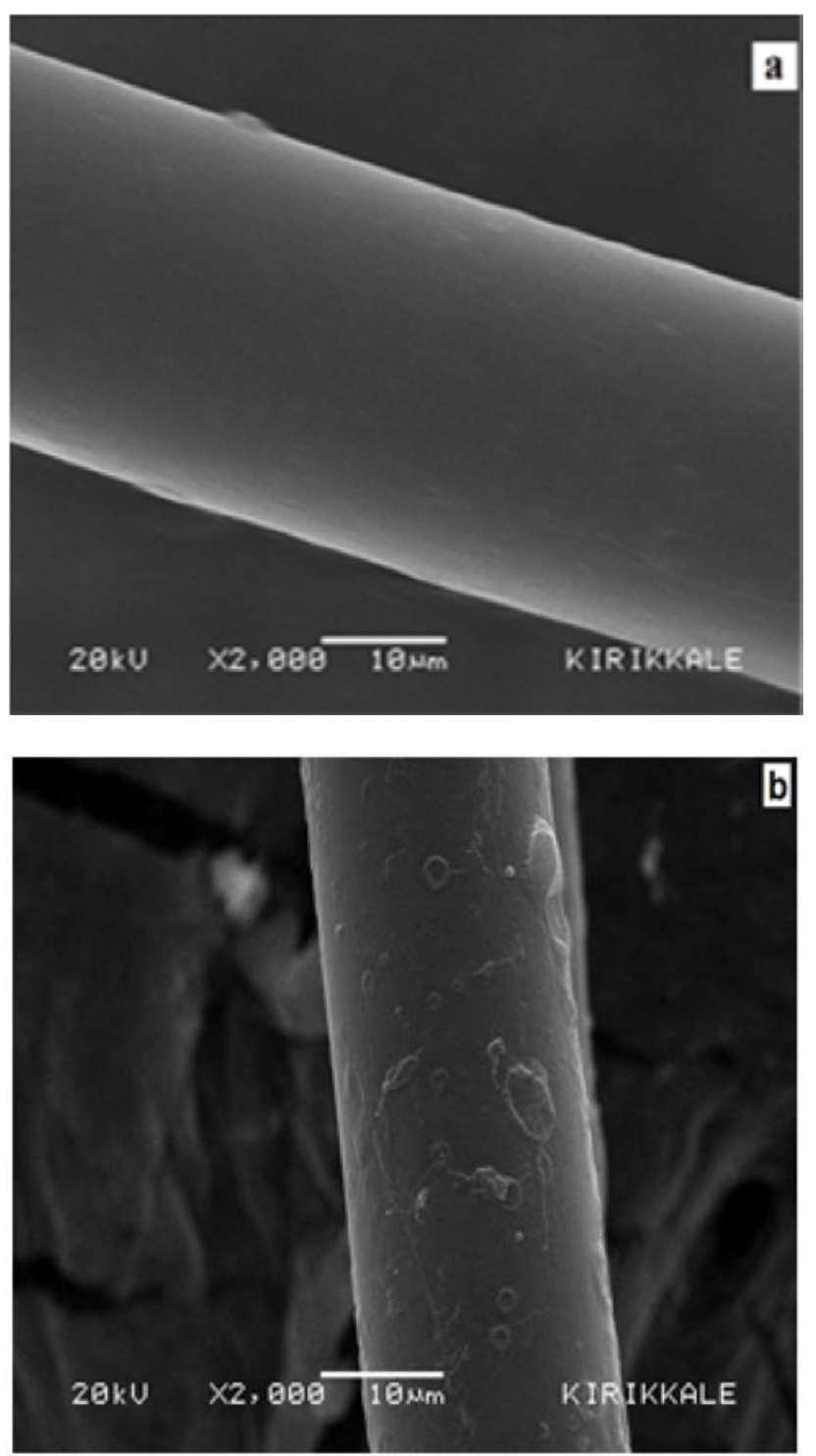

Figure 2. SEM micrographs of (a) ungrafted PET fibers and (b) GMA-gPET fibers (150\%). 


\subsection{IDA functionalization of GMA-g-PET fibers}

Iminodiacetate groups on glycidyl methacrylate-g-poly (ethylene terephthalate) fiber (IDA-GMA-g-PET) were attached by reacting diethyl iminodiacetate (DEIDA) with glycidyl methacrylate-g-poly (ethylene terephthalate) fiber (GMA-g-PET) and then hydrolysis of the ester introduced by $\mathrm{HNO}_{3}$ (Figure 4). The maximum value of conversion of epoxy groups to IDA was obtained from ethanol (50\%, v/v) as solvent. The effect of graft yield on the attached amount of IDA (\%) was investigated. The results are shown in Figure 3. The IDA (\%) increases significantly by increasing the graft yield up to $150 \%$, then falls upon further increase in graft yield. The amount of epoxy groups increased with increase in the graft yield. However, the decreasing trend showing in higher graft yield than optimum graft yield (150\%) may be due to the graft layer thickening with the increase in the graft yield [10].

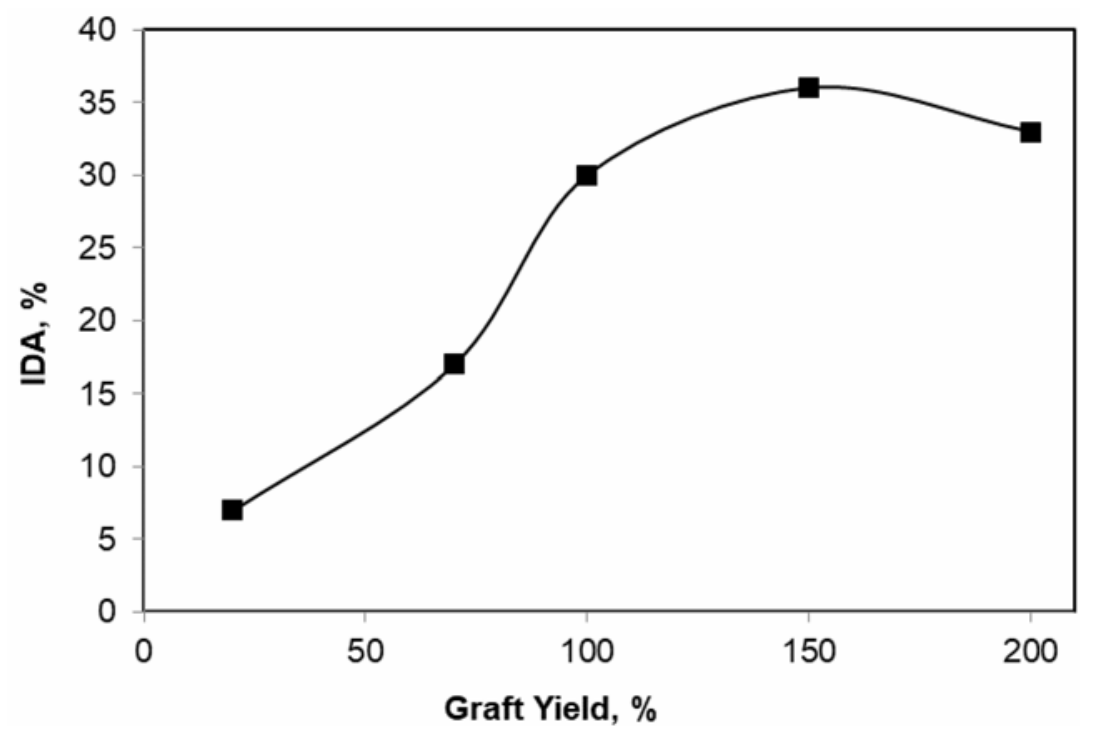

Figure 3. Effect of the graft yield on the attached amount of IDA (\%) on GMA-g-PET fibers. 

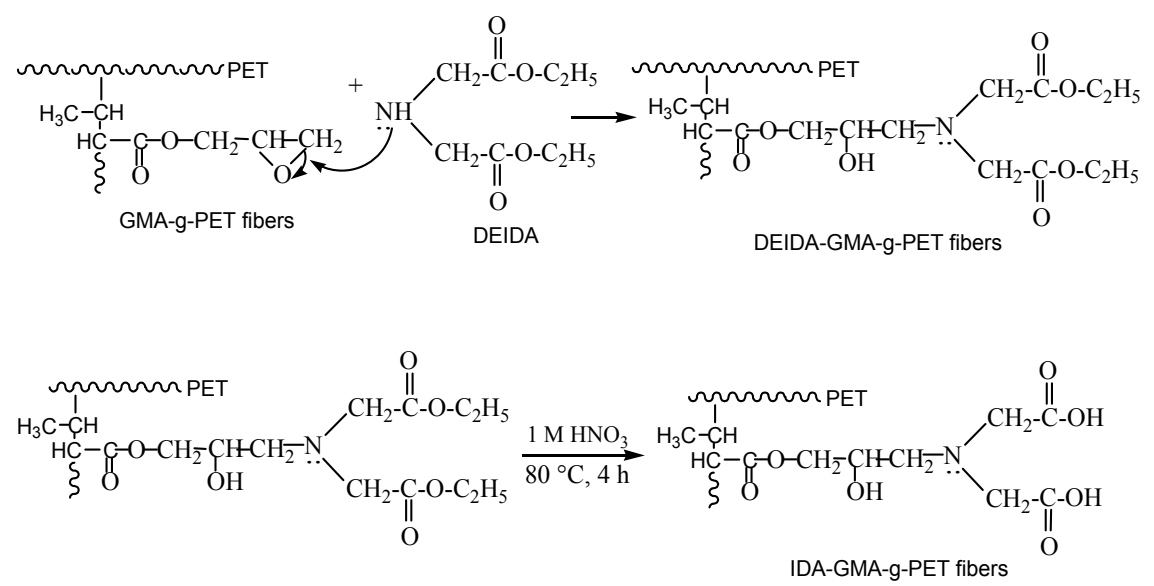

Figure 4. Reaction mechanism of IDA-GMA-g-PET fibers.

\subsection{Effect of $\mathrm{pH}$ value on removal}

The $\mathrm{pH}$ value of the solution highly influences the synthetic dyes removal capacity by chelating fiber adsorbents. The effect of $\mathrm{pH}$ on $\mathrm{MB}$ dye removal over the range 3-13 was investigated and shown in Figure 5. The results illustrate the removal capacity of MB obviously increases at high values of $\mathrm{pH}$. IDA-GMA-g-PET fibers showed distinctly higher MB dye removal capacity than DEIDA-GMA-g-PET and GMA-g-PET fibers throughout the $\mathrm{pH}$ range. The removal of MB dye on IDA-GMA-g-PET fibers increased from $8 \%$ to $100 \%$ in the $\mathrm{pH}$ ranging from 3 to 7 , and then it was approximately constant at $\mathrm{pH} 7-13$. This increase in the removal capacity was due to the availability of more active sites with increasing $\mathrm{pH}$. The effect of solution $\mathrm{pH}$ could be explained by considering the surface charge of the IDA-GMA-g-PET fibers and the ionic forms of the MB dye. It is necessary to examine various mechanisms such as electrostatic interaction, and chemical reaction which are responsible for adsorption on sorbent surface. At different $\mathrm{pH}$ values, the protonation and deprotonation would influence the surface structure of the IDAGMA-g-PET fibers, and dye ions would exist in different forms. Under acidic conditions, $\mathrm{H}^{+}$ions are abundant at its surface, where $\mathrm{COO}^{-}$groups 
and $\mathrm{H}^{+}$ions produce $\mathrm{COOH}$ groups. The carboxyl groups are present in nonionized form and no interaction can occur between the carboxyl groups and MB dye molecules which lead to the observed removal capacity reduction. On increasing the $\mathrm{pH}$, the carboxyl groups are ionized and the probability of interaction between the carboxylic groups and the cationic groups of MB increases. At higher $\mathrm{pH}$, the surface of IDA-GMAg-PET fibers may become negatively charged, which enhances positively charged MB dyes through electrostatic forces of attraction. The uptake of MB increases due to the dissociation of carboxylic groups suitable for coordination with MB. The similar mechanism was suggested in our previous work [19]. This may be illustrated as in Figure 6. Figure 7 shows the MB dye removal process.

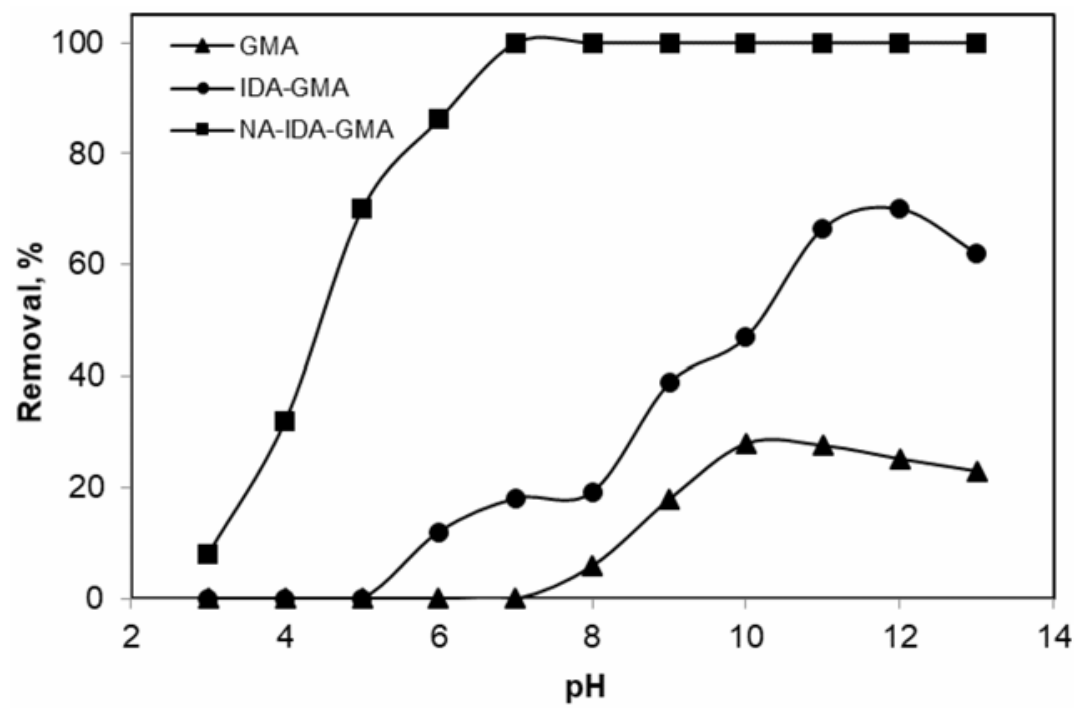

Figure 5. The $\mathrm{pH}$ dependence of MB dye removal by IDA-GMA-g-PET fibers (dye concentration $=20 \mathrm{ppm}$, temperature $=25^{\circ} \mathrm{C}$, contact time $=$ 60 min, graft yield $=150 \%$ ). 


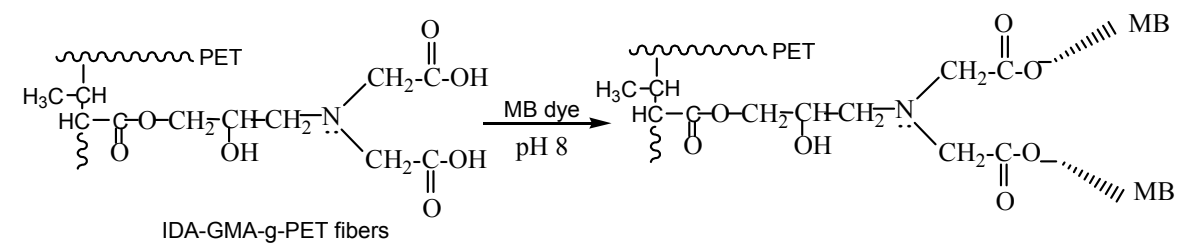

Figure 6. Removal of MB dye on the IDA-GMA-g-PET fibers.
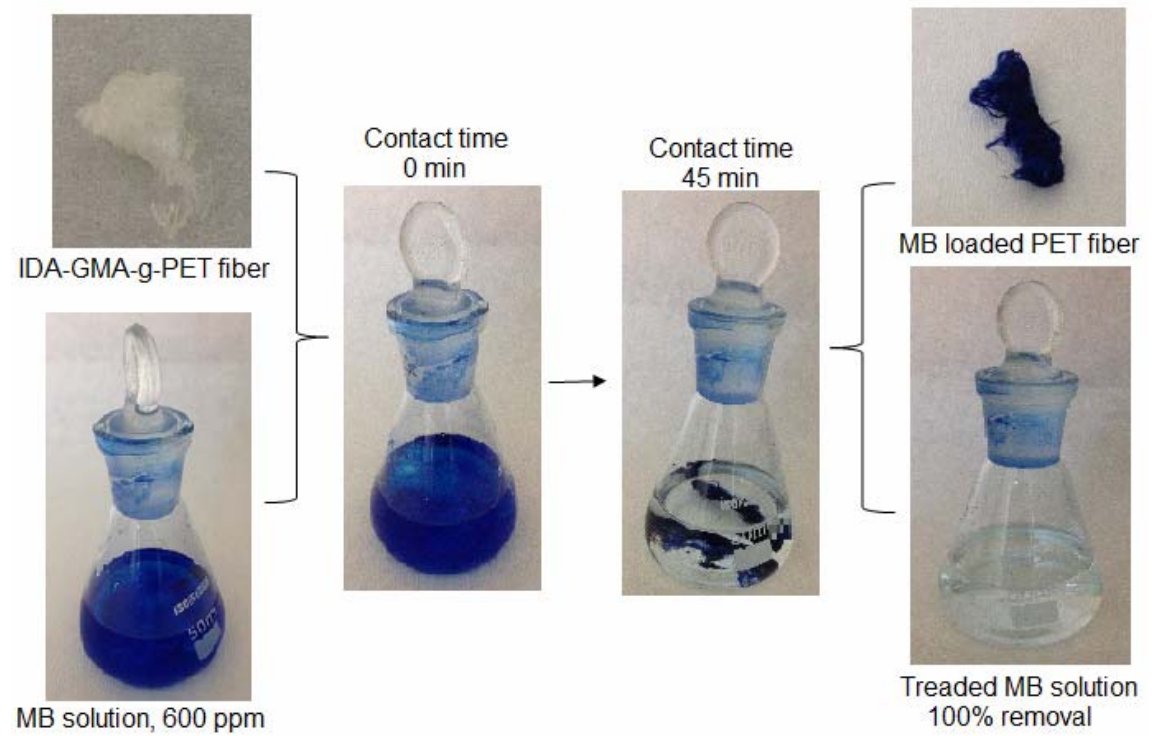

Figure 7. Photograph showing the MB dye removal process.

\subsection{Effect of removal time}

Removal time plays a key role in removal of dye on adsorbent surface. The removal amount of MB on IDA-GMA-g-PET fibers as a function of the removal time was plotted in Figure 8. It is observed that the removal takes place rapidly at first, then slows down and levels off. The removal equilibrium was attained within $45 \mathrm{~min}$. The rapid removal of the dye by chelating fiber adsorbent is significant for industrial use. Usually, removal kinetics includes two stages: the first initial removal stage is rapid and contributed to equilibrium uptake. It is thought to be outer surface removal due to the availability of many active removal sites. The second stage is slower and interpreted to be a gradual removal stage [20]. 


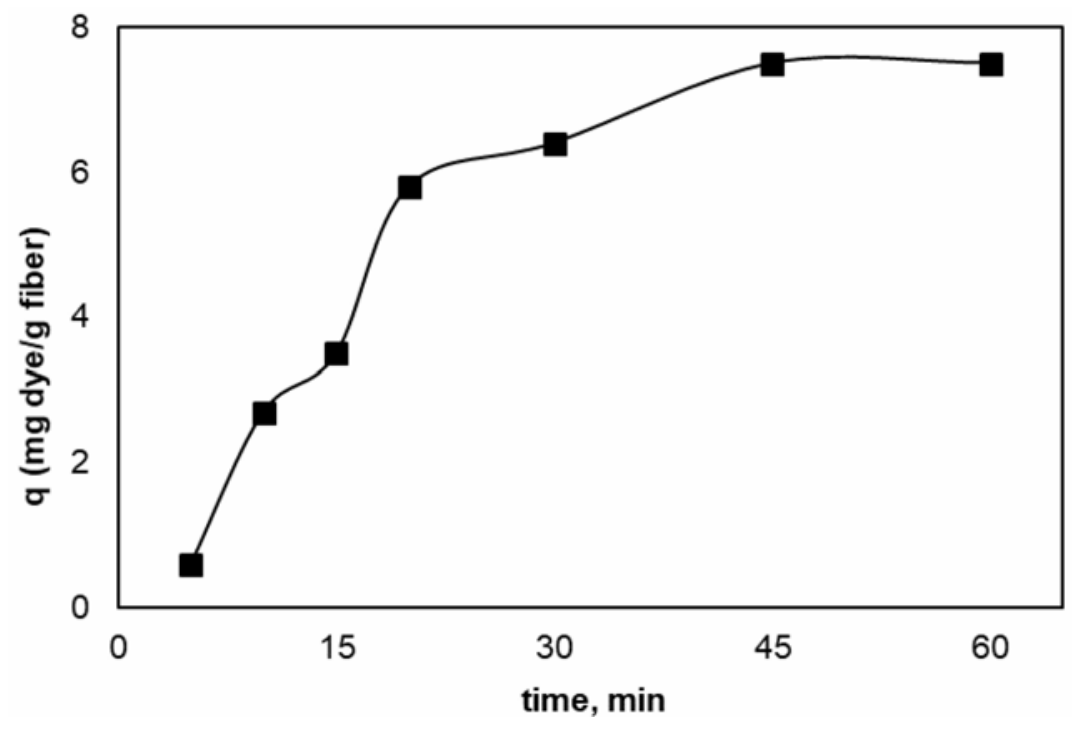

Figure 8. Relationship between adsorption time and removal of MB dye with IDA-GMA-g-PET fibers (dye concentration $=30 \mathrm{ppm}, \mathrm{pH}=9$, temperature $=25^{\circ} \mathrm{C}$, graft yield $=150 \%$ ).

\subsection{Effect of dye concentration}

The amount of dye adsorbed by the chelating fibrous adsorbent is dependent on the initial concentration of the dye. The effect of the concentration of $\mathrm{MB}$ dye on the removal capacity was studied in the range of $10-700 \mathrm{mgL}^{-1}$. Figure 9 shows the very high removal capacity against initial dye concentration. It is clear from that adsorption amount increased with the increase of initial dye concentration. IDA-GMA-g-PET fibers removed $100 \%$ of $\mathrm{MB}$ dye when initial concentration varied 10 to $600 \mathrm{mgL}^{-1}$ but after $600 \mathrm{mgL}^{-1}$, the percentage removal of dye up down $95 \%$. This may be explained by the availability of many removal binding sites during initial stage. MB dye which is water soluble and has a polar amino group present in the removal environment could interact with the active functional groups such as $-\mathrm{COO}^{-}$and $\mathrm{OH}^{-}$which are polar and very hydrophilic upon the IDA-GMA-g-PET fibers. These sites have anionic property that is suitable for dyeing with MB dye. Thus, IDA-GMA-g-PET fibers show very high removal capacity. 


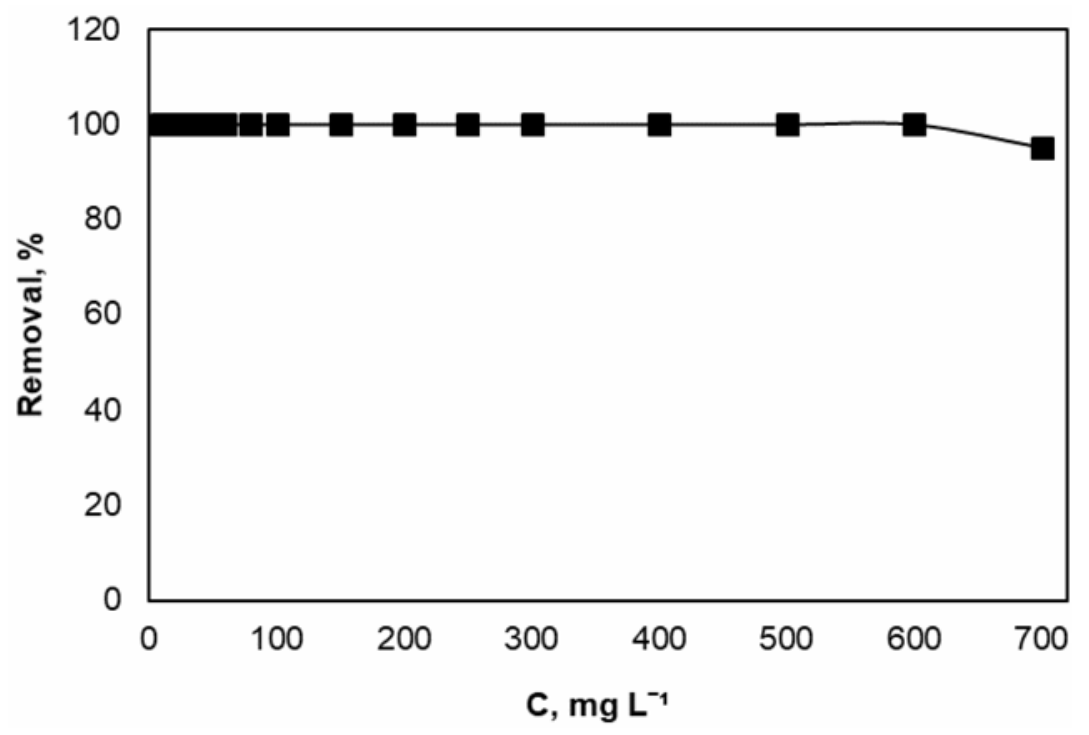

Figure 9. Effect of initial concentration of $\mathrm{MB}$ dye on removal $(\mathrm{pH}=9$, temperature $=25^{\circ} \mathrm{C}$, contact time $=45 \mathrm{~min}$, graft yield $=150 \%$ ).

\subsection{Desorption studies}

The desorption of MB dye is important for the regeneration of IDAGMA-g-PET fibers. IDA-GMA-g-PET fibers adsorbent did not adsorb MB dye significantly at $\mathrm{pH}<6$, that the adsorbed $\mathrm{MB}$ dye on the fibers adsorbent may be possibly desorbed in acidic solution with a low solution $\mathrm{pH}$ value. The percentage desorption profile is presented in Figure 10. It can be observed from this figure that the adsorbent can be regenerated in low acidic environment. The fiber adsorbent was regenerated around $100 \%$ at $1 \mathrm{M} \mathrm{HNO}_{3}$ after $1 \mathrm{~h}$ of operation. Desorption rate of $\mathrm{MB}$ dye from IDA-GMA-g-PET fibers were very high. IDA-GMA-g-PET fibers were eluted without losing its stability and activity. Thus, it should be effective a fiber adsorbent for the removal of MB dye.

Desorption studies can help elucidating the mechanism of a removal process. If the strong acids, such as $\mathrm{HNO}_{3}$ can desorb $\mathrm{MB}$ dye, it can be concluded that the attachment of MB dye on to the fibers adsorbent is by 
ion exchange or electro static attraction [21]. The investigation in the desorption studies confirms the mechanism of removal stated in the $\mathrm{pH}$ effect.

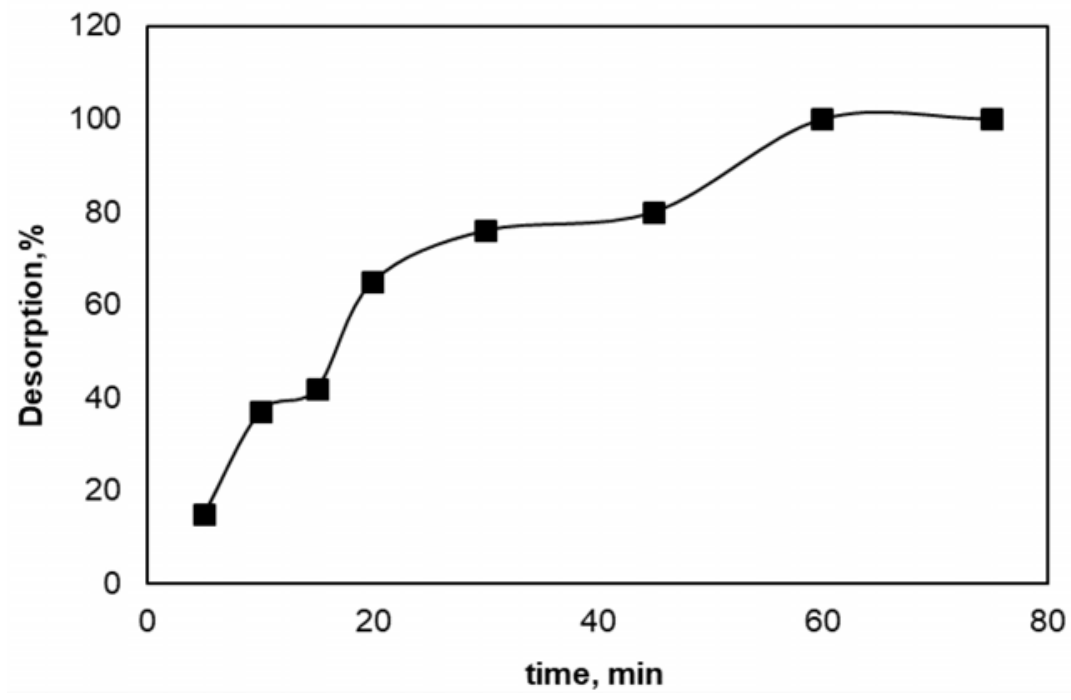

Figure 10. Effect of time on desorption (graft yield $=150 \%$, dye concentration $=20 \mathrm{ppm}$, temperature $=25^{\circ} \mathrm{C}$, solution $=1 \mathrm{M} \mathrm{HNO}_{3}$ ).

\subsection{Reuse of modified fibers}

Excellent reusability is desired to reduce the amount of fibers adsorbent, thereby lowering the material costs for MB dye removal. To indicate reusability of the IDA-GMA-g-PET fibers desorption cycles of MB dye was repeated ten times by using same the IDA-GMA-g-PET fibers. The regeneration of the fibers indicates that the fibers were used repeatedly for the removal MB dye without loss of dyes removal capacity as indicated Figure 11. Thus, due to the excellent recycling efficiency, IDA-GMA-g-PET fibers are used for practical applications. 


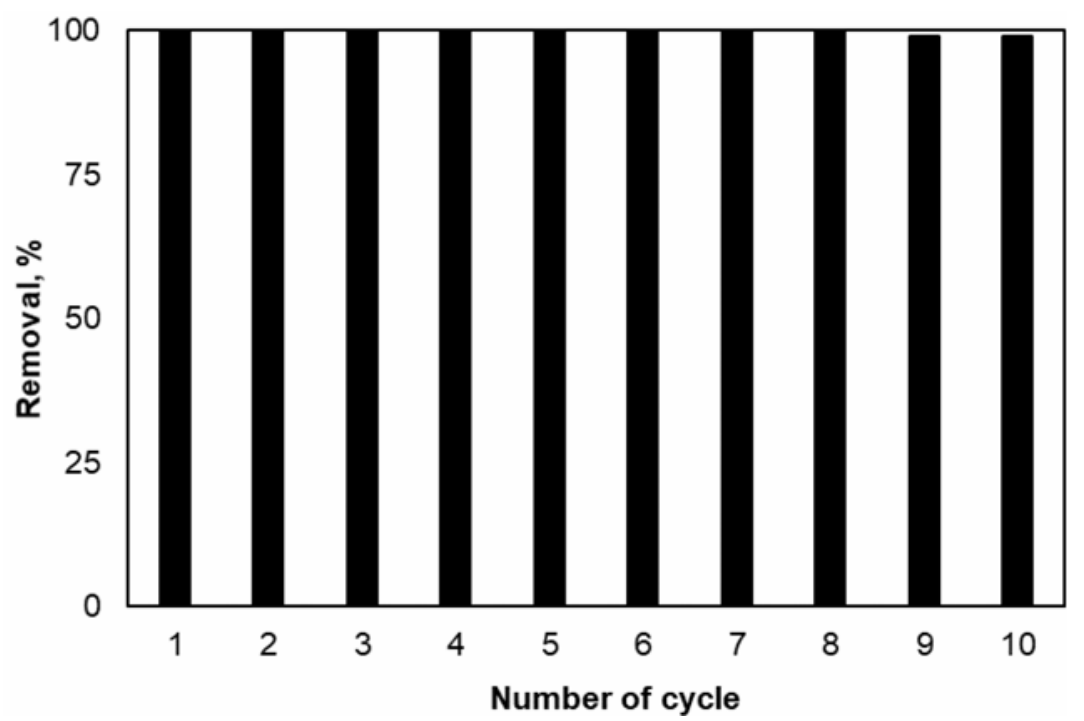

Figure 11. Effect of number of cycle on the percent removal of MB dye on IDA-GMA-g-PET fibers.

\section{Conclusion}

In this study, a chelating fibers containing IDA have been identified as potentially and efficient adsorbent for removal MB dye. Chelating fibrous adsorbent containing IDA groups were prepared by reaction between IDA groups and epoxy groups on GMA-g-PET fibers synthesized by the graft copolymerization technique. Removal MB dye from aqueous solution by IDA-GMA-g-PET fibers was investigated. The maximum value of modification of epoxy groups to IDA onto GMA-g-PET fibers was obtained at graft yield $150 \%$. It was observed that $\mathrm{pH}$ is the most important parameter. IDA-GMA-g-PET fibers removed $100 \%$ of MB dye (up to 600ppm) at optimum $\mathrm{pH}$. A treatment time of $45 \mathrm{~min}$ was sufficient to reach the removal equilibrium value. MB dye adsorbed onto IDAGMA-g-PET fibers was desorbed by using $1 \mathrm{M} \mathrm{HNO}_{3}$. The fiber adsorbent can be used repeatedly in the removal-regeneration cycle without any loss of removal capacity. It was recognized that IDA-GMA-g- 
PET fibers have an advantage of fast removal, high removal capacity, good reusability, and high chemical stability. The fiber adsorbent should be addressed for other cationic dyes. In the future, it could be applied in wastewater contaminated with cationic dyes.

\section{Acknowledgement}

The authors are grateful to the Kirıkkale University Research Fund for the financial support for this work.

\section{References}

[1] M. Rafatullah, O. Sulaiman, R Hashim and A. Ahmad, Adsorption of methylene blue on low-cost adsorbents: A review, Journal of Hazardous Materials 177(1-3) (2010), $70-80$.

DOI: https://doi.org/10.1016/j.jhazmat.2009.12.047

[2] I. M. Banat, P. Nigam, D. Singh and R. Marchant, Microbial decolorization of textiledyecontaining effluents: A review, Bioresource Technology 58(3) (1996), 217-227.

DOI: https://doi.org/10.1016/S0960-8524(96)00113-7

[3] L. Qiong and W. Yanbo, Dyes wastewater treatment via electrochemical oxidation, Fresenius Environmental Bulletin 26(12A) (2017), 7756-7759.

[4] T. Panswad and S. Wongchaisuwan, Mechanisms of dye wastewater colour removal by magnesium carbonate-hydrated basic, Water Science and Technology 18(3) (1986), 139-144.

DOI: https://doi.org/10.2166/wst.1986.0045

[5] Y. E. Miao, R. Wang, D. Chen, Z. Liu and T. Liu, Electrospun self-standing membrane of hierarchical $\mathrm{SiO}_{2} @ \gamma-\mathrm{AlOOH}$ (Boehmite) core/sheath fibers for water remediation, ACS Applied Materials \& Interfaces 4(10) (2012), 5353-5359.

DOI: https://doi.org/10.1021/am3012998

[6] K. Swaminathan, S. Sandhya, A. Carmalin Sophia, K. Pachhade and Y. V. Subrahmanyam, Decolorization and degradation of $\mathrm{H}$-acid and other dyes using ferrous-hydrogen peroxide system, Chemosphere 50(5) (2003), 619-625.

DOI: https://doi.org/10.1016/S0045-6535(02)00615-X

[7] A. Alinsafi, M. Khemis, M. N. Pons, J. P. Leclerc, A. Yaacoubi, A. Benhammou and A. Nejmeddine, Electro-coagulation of reactive textile dyes and textile wastewater, Chemical Engineering and Processing: Process Intensification 44(4) (2005), 461-470.

DOI: https://doi.org/10.1016/j.cep.2004.06.010 
[8] Y. Xing and G. Wang, Poly(methacrylic acid)-modified sugarcane bagasse for enhanced adsorption of cationic dye, Environmental Technology 30(6) (2009), 611-619.

DOI: https://doi.org/10.1080/09593330902838098

[9] L. Wang, J. Zhang and A. Wang, Fast removal of methylene blue from aqueous solution by adsorption onto chitosan-g-poly (acrylic acid)/attapulgite composite, Desalination 266(1-3) (2011), 33-39.

DOI: https://doi.org/10.1016/j.desal.2010.07.065

[10] N. C. Dafader, N. Rahman, S. K. Majumdar, M. R. Khan and M. Rahman, Preparation and characterization of iminodiacetate group containing nonwoven polyethylene fabrics and its application in chromium adsorption, Journal of Polymers and the Environment 26(2) (2018), 740-748.

DOI: https://doi.org/10.1007/s10924-017-0991-8

[11] M. Yiğitoğlu and M. Arslan, Selective removal of $\mathrm{Cr}(\mathrm{VI})$ ions from aqueous solutions including $\mathrm{Cr}(\mathrm{VI}), \mathrm{Cu}$ (II) and $\mathrm{Cd}(\mathrm{II})$ ions by 4 -vinly pyridine/2-hydroxyethylmethacrylate monomer mixture grafted poly(ethylene terephthalate) fiber, Journal of Hazardous Materials 166(1) (2009), 435-444.

DOI: https://doi.org/10.1016/j.jhazmat.2008.11.075

[12] M. Arslan, Use of 1,6-diaminohexane-functionalized glycidyl methacrylate-gpoly(ethylene terephthalate) fiber for removal of acidic dye from aqueous solution, Fibers and Polymers 11(2) (2010), 177-184.

DOI: https://doi.org/10.1007/s12221-010-0177-7

[13] R. K. Misra, S. K. Jain and P. K. Khatri, Iminodiacetic acid functionalized cation exchange resin for adsorptive removal of $\mathrm{Cr}(\mathrm{VI}), \mathrm{Cd}(\mathrm{II}), \mathrm{Ni}(\mathrm{II})$ and $\mathrm{Pb}$ (II) from their aqueous solutions, Journal of Hazardous Materials 185(2-3) (2011), 1508-1512.

DOI: https://doi.org/10.1016/j.jhazmat.2010.10.077

[14] C. Noureddine, A. Lekhmici and M. S. Mubarak, Sorption properties of the iminodiacetate ion exchange resin, amberlite IRC-718, toward divalent metal ions, Journal of Applied Polymer Science 107(2) (2008), 1316-1319.

DOI: https://doi.org/10.1002/app.26627

[15] S. Konishi, K. Saito, S. Furusaki and T. Sugo, Binary metal-ion sorption during permeation through chelating porous membranes, Journal of Membrane Science 111(1) (1996), 1-6.

DOI: https://doi.org/10.1016/0376-7388(95)00237-5

[16] M. Yiğitoğlu and M. Arslan, 4-Vinylpyridine and 2-hydroxyethylmethacrylate monomer mixture graft copolymerization onto poly(ethylene terephthalate) fibers using benzoyl peroxide, Polymer Bulletin 58(5-6) (2007), 785-798.

DOI: https://doi.org/10.1007/s00289-006-0719-8 
[17] M. Arslan, Preparation and use of amine-functionalized glycidyl methacrylate-gpoly(ethylene terephthalate) fibers for removal of chromium(VI) from aqueous solution, Fibers and Polymers 11(3) (2010), 325-330.

DOI: https://doi.org/10.1007/s12221-010-0325-0

[18] E. S. Dragan, M. V. Dinu, G. Lisa and A. W. Trochimczuk, Study on metal complexes of chelating resins bearing iminodiacetate groups, European Polymer Journal 45(7) (2009), 2119-2130.

DOI: https://doi.org/10.1016/j.eurpolymj.2009.03.012

[19] M. Arslan and M. Yiğitoğlu, Use of methacrylic acid grafted poly(ethylene terephthalate) fibers for the removal of basic dyes from aqueous solutions, Journal of Applied Polymer Science 110(1) (2008), 30-38.

DOI: https://doi.org/10.1002/app.28421

[20] V. K. Garg, R. Kumar and R. Gupta, Removal of malachite green dye from aqueous solution by adsorption using agro-industry waste: A case study of Prosopis Cineraria, Dyes and Pigments 62(1) (2004), 1-10.

DOI: https://doi.org/10.1016/j.dyepig.2003.10.016

[21] I. D. Mall, V. C. Srivastava, G. V. A. Kumar and I. M. Mishra, Characterization and utilization of mesoporous fertilizer plant waste carbon for adsorptive removal of dyes from aqueous solution, Colloids and Surfaces A: Physicochemical and Engineering Aspects 278(1-3) (2006), 175-187.

DOI: https://doi.org/10.1016/j.colsurfa.2005.12.017 